\title{
Carrot-or-Stick: How to Trigger the Digitalization of Local Owner Operated Retail Outlets?
}

\author{
Lars Bollweg \\ South Westphalia \\ University of Applied \\ Sciences \\ bollweg.lars@ \\ fh-swf.de
}

\author{
Richard Lackes \\ TU Dortmund \\ richard.lackes@, \\ tu-dortmund.de
}

\author{
Markus Siepermann \\ TU Dortmund \\ markus.siepermann@ \\ tu-dortmund.de
}

\author{
Peter Weber \\ South Westphalia \\ University of Applied \\ Sciences \\ Weber.peter@ \\ fh-swf.de
}

\begin{abstract}
Local Owner Operated Retail Outlets (LOOROs) are threatened in their very existence by the digitalization pressure from online and offline competitors on the one hand and by changing shopping habits of their customers on the other. Despite all digitally-enabled opportunities to regain competitive power, LOOROs still hesitate to adopt digital tools and applications. Politicians, city managers and retail lobbies seek for triggers to support the local structures and to push the digitalization efforts of local retailers. Building on Andreoni's "Carrot-and-Stick Approach", this study examines the impact of the availability of resources (carrot) and the perception of pressure (stick) on the use of digital applications among 223 owners of LOOROs from 26 cities in Germany. Our findings show that LOOROs are receptive for "Carrot-andStick”. LOOROs seek for orientation while suffering under a shortage of time and capacities and seem to be disconnected from the development of their competitors and their customers.
\end{abstract}

\section{Introduction}

In a growing market environment, local owner operated retail outlets (LOOROs) are pressured to adapt their own business models to the intense competitive situation in the retail sector. LOOROs, which are characterized by a small-sized store area, a limited number of staff and high owner-involvement in the day-to-day business operations, are challenged by the industry transformation [1]. In Germany, the market share of the business type LOORO has declined from $26 \%$ to $18.5 \%$ between the years 2003 and 2014 [2]. Additionally, several independent studies predict a decline in revenues of $30 \%$ in the next four years in Germany $[3,4]$. Responsible for this development is on the one hand the online trade that challenges LOOROs with strong price and service competition, while, at the same time, former purely internet-based retailers have started expanding its operations by means of physical stores in city centers to conquer the last bastion of brick and mortar retail, the customers in the high streets. Moreover, big-box retail outlets and chain stores have started to digitalize their business models and offer multichannel sales and services to their local customers [5]. Customers, on the other hand, have changed their buying habits: they are already used to online shopping and digital services so that their shopping frequency in city centers is declining [6]. To sum it up, pure online retailers, big-box retail outlets and chain stores as well as changing customer shopping habits and a decline in shoppers' frequencies in the high streets are threatening the very existence of LOOROs. However, LOOROs are not defenselessly exposed to the threats of the digital age. Digital tools and applications to handle administrative tasks (e.g. digital inventory management systems, customer relationship management systems and marketing tools) and to enable digital interaction with the customers across the sales channels (e.g. via online shops, e-marketplaces, in-store applications, digital shelf extensions) allow LOOROs to overcome their inherent limitations (e.g. lack of time, lack of knowledge, lack of human resources, lack of finance, etc.) and to regain competitive power [7]. Despite all opportunities, studies show that LOOROs, like other small- and medium-sized enterprises (SME), still hesitate to adopt digital tools for their own business $[7,8]$.

The transformation of the retail sector and the slow but steady dying of the small, owner-operated retailers is not just a matter of the LOOROs themselves. Abandoned high streets and empty city centers are potential threats to the traditional infrastructures and might have a negative impact on related industries (gastronomy, tourism, and many more) as well as on the local job markets. Therefore, politicians, city managers and the 
retail lobbies seek for triggers to support the local structures and to push the digitalization efforts of the local retailers in this uncertain phase of industry transformation. With regards to the Economic Theory of Regulations (ET), the government and the public sector use two types of measures to foster the desired development: 1) Subsidies including measures that add or improve access to resources for development (e.g. grants, loans, loan guarantees, vouchers, contracts, etc.) and 2) Regulations including measures that create pressure towards desired development (e.g. legal, economic and social regulations, public information, taxes, liability, etc.) $[9,10]$. The application of this two-sided toolbox is called the "Government's Carrot-and-Stick Approach" [11].

The purpose of this study is to examine the impact of subsidy (carrot: offering resources) and regulation (stick: creating pressure) based triggers to foster the use of digital tools and applications among LOOROs. Therefore, we want to understand:

RQ1: Are LOOROs receptive for triggers based on resources (carrot) and pressure (stick)?

And furthermore:

RQ2: What are promising measures for a "CarrotAnd-Stick" approach to foster the current use of digital tools and applications among LOOROs?

To achieve meaningful results, we conducted a survey among 223 owners of LOOROs of 26 comparable cities (rural region and population below 100,000 inhabitants) in Germany. The results of this study offer insights for the public sector on how to promote the digitalization of LOOROs as well as insights for owners of LOOROs on promising starting points for their own digital development. Our results contribute to the body of knowledge on two levels: 1) insights on the effects of "Available Resources" (Carrot) and "Perceived Pressures" (Stick) on the intention to use and the current usage of digital tools and applications in the front-end and back-end activities of LOOROs and 2) insights on the orchestration of an efficient and effective "Carrot-And-Stick" approach.

The remainder of this paper is structured as follows: In section 2, we provide an overview about the related theory with regards to subsidies and regulations. In section 3, we develop a conceptual model based on the above-mentioned theories to address our research question. In section 4 , we describe the survey conducted and provide the statistical analysis. Further, we discuss our findings in section 5 and point out research, managerial and political implications in section 6. Finally, we conclude in section 7 in order to answer the initial research question, to highlight limitations and to point out future research opportunities.

\section{Theoretical Background}

This study is addressing an intensively discussed area: the implication of governmental and public interventions with regards to technology adoption among commercial industries. Beside politicians and citizens also economists support controversial viewpoints about the use of public resources and powers to improve the economic status of members of the public (private or corporations) e.g. Keynesianism vs. Monetarism. As this study does not aim to resolve this controversy neither to argue for one or the other, we draw the attention towards literature that explains subsidies (carrot) and regulations (stick) and exposes implications for the technology adoption.

The Economic Theory of Regulation regarded market failure as the motivating reason for enacting regulations. Once established, regulatory bodies were supposed to lessen or eliminate the inefficiencies engendered by the market failure [12]. The available measures for the government and the public sector to foster the desired development are divided into subsidies and regulations $[9,10]$. Subsidies are state transfers to members of the public which are either in kind or of monetary nature. Regulations are considered as the employment of legal instruments for the implementation of social-economic policy objectives [13]. The counterpart to regulation is deregulation; it means the state's withdrawal of its legal powers to direct the economic conduct (e.g. pricing, market entry) of members of the public. A fully functional market is a prerequisite for the successful implementation of deregulation [12].

Existing IS research neglects the examination of impacts of subsidies (carrot) and regulations (stick) on the technology adoption at an industry and firm level. A structured literature search in the databases of ScienceDirect, EbscoHost and Google Scholar remained fruitless. Minor effects of governmental regulations are discussed in technology adoption models like the "Technology-Organization-Environment-Framework (TOE)" without differentiating the governmental toolbox into subsidies and regulations [14]. These models process governmental regulations as given parameters companies are required to comply with $[15,16]$. However, extensive research on subsidies and regulations is done at an industry-level in highly regulated markets (e.g. renewable energy and agriculture) $[17,18]$. For the research on highly regulated markets, we discovered two main examination areas: 1) impact of subsidies and regulations on consumer prices and 2) the impact on industry growth. None of the reviewed literature was related to the impacts of governmental triggered technology adoption among economic groups at the firm level. The lack of research in this direction 
might be attributable to the favorable market conditions in the retail sector over the past decades. Nowadays, the retail market is jeopardized because of the challenges of the digital age and is failing due to financial and technological imbalances $[5,6]$. The existence of market failure is often the reason that self-regulatory organizations and governments intervene in a particular market [14]. Therefore, the government and the public sector are seeking triggers to lessen the imbalances of the market; this research takes a step towards identifying these triggers.

\section{Conceptual Model \& Research Framework}

To support current public efforts and which in turn foster LOOROs and their current state of digitalization, this study aims to examine the possible external triggers of the governmental "carrot-and-stick approach" to push the use of digital tools and applications among LOOROs. Therefore, we examine whether and how "available resources" (carrot) and "perceived pressures" (stick) influence the owners of local retail outlets to use digital technologies. To frame the ambiguity of the umbrella term digitalization into an operational understanding, we structure the digital tools and applications based on the operational view of the management process of business models: 1) The digitalization of the front-end sales channels where we collect all digitalization efforts with direct customer touch points, and 2) the digitalization of the administrative back-end, invisible to the customer [19].

LOOROs are in fact micro-enterprises where owners are intensively involved in the day-to-day operations and which have to handle a structural shortage of internal and external resources [8]. Due to this characteristics, common small, medium and large enterpriserelated technology adoption approaches (e.g. the Technology-Organization-Environment Framework (TOE), Technology Acceptance Model (TAM), Theory of Planned Behavior (TPB), Combined TAM and TPB, TAM2, Diffusion of Innovations Theory, and many more) are not suitable [20]. In large firms decisions are subject to collective, collaborating scrutiny and testing, and are influenced by others to a much higher degree than in micro-enterprises. In LOOROs the owner is the executive manager, salesman, and storekeeper in personal union. Hence, the owner-managers of LOOROs are the company's key decision makers who are in turn rather influenced by external factors than by internal structures [21]. To meet these characteristics this study will exclude the impacts of the organizational level from the research model and focuses on an ownercentric examination based on the individual level of the owner's personal characteristics.
The framework of the model is built on the S-O-R Model. The origin of the S-O-R Model lies in the field of environmental psychology. Mehrabian and Russel (1974) postulate that environmental stimuli (S) lead to emotional reactions of the organism $(\mathrm{O})$ which finally drives behavioral response (R). To describe human perception of their encountered environments, the original S-O-R Model used three emotional dimensions: pleasure, arousal and dominance (the PADScale). In the field of environmental psychology, pleasure, arousal and dominance are conceived as three basic dimensions of emotional responses that indicate peoples' state of feeling. Mehrabian and Russel (1974) described pleasure purely in terms of positive or negative feelings. Arousal is described as a feeling state that concerns mental activity and dominance as a feeling of control and behavior restrictions caused by physical or social barriers [22].

In marketing research the S-O-R Model is usually used to examine the response of customers to a situational or environmental stimulus e.g. colors in a store environment or music while online shopping. Wang et al. (2011) used an S-O-R approach to examine how the two dimensions of web aesthetics, aesthetic formality and aesthetic appeal influence online consumers' psychological reactions. Moreover, Lee et al. (2011) applied a S-O-R based model to investigate how hightechnology attributes influence consumer responses. By means of S-O-R Zhang et al. (2014) examined the motivation of customers to participate in social commerce and the impact of technological environments and virtual customer experience. Despite the contribution of the S-O-R framework to the research of consumer behavior, Kim et al. (2016) and other research papers point out that there is an issue with its PADScale which measures consumers' emotional responses to environmental stimuli on bipolar continua. Several studies criticize the bipolar conceptualization for allowing the joint occurrence of pleasant and unpleasant states and propose a unipolar view as more suitable $[26,27,28]$. In an attempt to overcome this issue, the latest reviews of the "PAD-Scale" by Bakker et al. (2014) had highlighted that the three dimensions of the PAD-Scale can be linked to one joint model of attitudes: pleasure, arousal and dominance can be respectively affective (feeling), cognitive (thinking) and conative (acting) responses. According to Bakker, the triad of feeling, thinking and acting can be unified as one joint measure for the organism (O) [29].

This finding stands in line with the long history of information systems research about the use of technology in organizations. IS research has provided a broad range of theories with regard to technology adoption, acceptance and implementation, extent of usage, effectiveness, success as well as satisfaction [20]. Some of 
the perspectives are regarded as theories about diffusion of technology and discuss the adoption of technology through different channels [30]. Other perspectives focus on human behavior and its impact on the decision-making process towards the adoption and usage of technology $[31,32]$. While related theories of technology diffusion are helpful to explain technology adoption outcomes on an organizational level behavioral theories contrarily focus on the individual analysis level where human behavior has its impact. The Theory of Reasoned Action (TRA) [33] and its successor the Theory of Planned Behavior (TPB) by Ajzen (1991) stated that attitudes, control beliefs and subjective norms influence behavioral intention, what in turn influences the actual behavior. Davis (1989) applied TRA / TPB to the individual level of technology adoption behavior in his well-known "Technology Adoption Model (TAM)". According to Davis, two key constructs influence an individual's intention to use a technology namely the "Perceived Usefulness" and "Perceived Ease of Use". Over the last two decades researchers extended this view, examined antecedent as well as moderating factors and incorporated alternative belief factors into their research models like the TAM2 or the UTAUT Model while keeping the core structures (behavioral intention influences actual behavior). Furthermore, researchers used the TRA / TPB as core framework and integrated theory of related disciplines. Kourfaris (2002) used constructs from information systems (TAM), marketing (Consumer Behavior), and psychology (Flow and Environmental Psychology) in an integrated theoretical framework of online consumer behavior to examine how emotional and cognitive responses to visiting a Web-based store for the first time can influence online consumers' intention to return [34].

Accordingly, we build our research framework on the S-O-R framework and extend its organism (O) section with the integration of the core constructs of TRA, TPB and TAM, namely "attitude", "behavioral intention" and "actual behavior".

Stimulus (S): Despite the growing competition from the online trade, digitalized advanced big box retail outlets and chain stores as well as changing customer habits towards digital channels LOOROs still hesitate to use digital tools and applications to regain competitive power $[7,8]$. To support LOOROs, politicians, city managers and the retail lobbies seek for triggers to push the digitalization efforts of the local retailers. The toolbox of the public sector comprises two types of measures to promote the desired development: 1) Subsidies (adding resources) and 2) Regulations (creating pressure) [9]: the "Government's Carrot-and-Stick Approach" [11]. The prospects of success of the applicable measures (adding resources or creating pressure) are related to the state of the availability of resources and the perception of pressure among the aimed target group. In detail, a state of high available resources and a low perception of pressure would have a lower impact on the prospects of success. Vice versa, a state of low available resources and a high perception of pressures would be promising for the prospects of success of the applied measures [9].

To examine the potential effectiveness of the discussed measures, this study investigates the current availability of resources and the perception of pressures among LOOROs as well as their impact on the usage of digital tools and applications. Mehrabian and Russel (1974) state that environmental stimuli (S) lead to emotional reaction of the organism $(\mathrm{O})$. The perception of the availability of resources and the perception of external pressures can be both seen as comparable environmental stimuli that lead to comparable emotional reactions of the organism. According to Bakker (2014), we will link the commonly used PAD- Scale in the organism $(\mathrm{O})$ block to a joint model of attitudes to avoid the joint occurrence of pleasant and unpleasant states.

Our measurement of the "Available Resources" is based on the resource categories of the Resource-Based View. These categories are representing tangible and intangible goods and can be translated into the availability of financial resources (R1), the availability of the necessary capacities (R2), the availability of the needed knowledge (R3) and the availability of time (R4) [35]. To investigate the influence of available resources on the emotional reactions of the organism $(\mathrm{O})$ block of the research model, we hypothesize:

H1: The availability of resources has a positive influence on the attitude towards the digitalization.

Regarding the effectiveness of measures that use pressure to foster digital developments among LOOROs, this study also investigates the current state of the perception of external pressures and their influence on the organism $(\mathrm{O})$ of the research model. Our measurement of the "Perceived Pressure" is derived from the "Three-Environment Theory" [36]. Correspondingly, external pressures comprise influences from the near and far environment. As described in the Three-Environment Theory, the near (specific) environment is formed by influences of competitors (EP1 competitive pressure), customers (EP2 - customer pressure) and suppliers who exert a direct impact on the examined organization. The far (general) environment is formed by influences of politics (EP3 - legal pressure), society (EP4 - society pressure), technological and economic pressures [36]. With respect to the discussed background we are mainly covering the economic pressure with the investigation of the financial resources but we neglect the suppliers' pressure 
(based on offer and demand) and the technological pressure (push and pull) due to our research scope of potential triggers for the public sector. Accordingly, we hypothesize:

H2: Perceived pressure towards digitalization has a positive influence on the attitude towards the digitalization.

Organism (O): In the traditional S-O-R models the $(\mathrm{O})$ is represented by the PAD-Scale and its measure of pleasure, arousal and dominance. Despite the undoubted contributions of the S-O-R model for consumer research, the PAD-Scale itself is questionable [29]. To address the criticism about the bipolar conceptualization, namely the joint occurrence of pleasant and unpleasant states in the PAD-Scale [25,26], this study integrates the core blocks of the established TRA/TPB theory that derives from the well-known Technology Acceptance Model (TAM). In contrast to the suggested triade of feeling, thinking, and acting by Bakker (2014), TRA/TPB theory separates the internal state of acting (behavior) from the measurement of the attitude (feeling and thinking). TRA/TPB theory states that attitudes, control beliefs and subjective norms do not directly influence actual behavior. Furthermore, it states that attitudes influence the behavioral intention (intention to use) which in turn influences the actual behavior (current use) [31,32].

Our joint measurement of the attitude towards digitalization is based on TRA / TPB theory. The feeling is represented by the measurement of the subjective norm towards digitalization (A1) and the ease of use (A2). The thinking is covered by the expected future developments (A3) and the expected effectiveness of the digitalization (A4) [31,32]. According to the introduced relationships of the TRA/TPB theory we state the following hypotheses for both of our examination areas (front-end and back-end):

HЗa: A positive attitude towards digitalization has a positive influence on the intention to use digital sales channels (front-end).

$\mathrm{H} 3 \mathrm{~b}$ : A positive attitude towards digitalization has a positive influence on the intention to use the digital tools in the administration (back-end).

Our measurement (behavioral) intention to use digitalization in both examination areas (front-end and back-end activities) is based on the operational view of the management process of business models for brick and mortar retail stores [19]. For the front-end (intention to use digital sales channels), it covers the possible online and offline sales channels such as an own online shop (IS1), the presence on third-party e-marketplaces (IS2) and the use of in-store applications (IS3) as well as the online marketing activities (IS4) [19].

Our measurement for the back-end (intention to use digital tools and applications in the administration) covers all digital support activities with no direct customer touch points [19]. As there are: the use of software for administration (IA1), the use of inventory management systems (IA2), the use of digital communication channels (IA3) and the use of digital payment systems (IA4).

According to TRA/TPB theory attitudes influence the behavioral intentions what in turn influences the actual behavior, we consequently state the following hypotheses [31,32]:

H4a: A high intention to use digital sales channels has a positive influence on the current use of digital sales channels.

$H 4 b$ : A high intention to use the digital tools in the administration has a positive influence on the current use of the digital tools in the administration.

Response (R): The usage of digitalization either in front-end or back-end activities is measured as indirect response to the examined stimuli, "Available Resources" and "Perceived Pressures". It is the last step in the already introduced chain of relationships, stated by the TRA/TPB theory [31,32]. Our last measurement of the current use of digitalization for both examination areas shares the same theoretical structure with the intentional constructs [19]. Instead of behavioral intentions we examine the actual behavior. For the "Current Use of digital Sales Channels" we cover the already introduced possible online and offline sales channels: online shop (US1), third-party e-marketplaces (US2), in-store applications (US3) and online advertisement (US4). For the "Current Use of digital Administration" we cover the back-end activities of the LOOROs namely the use of software for administration (UA1), the use of inventory management System (UA2), the use of digital communication channels (UA3) and the use of digital payment systems (UA4).

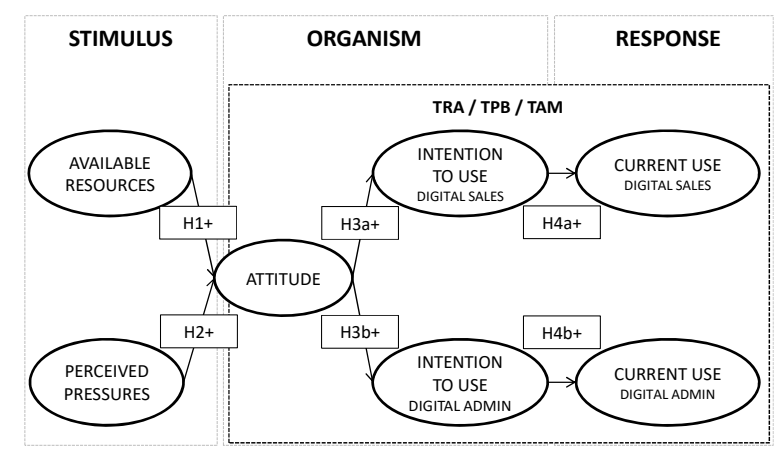

Figure 1: Research Model 


\section{Analysis}

\subsection{Data Collection}

As part of the research project "Future Lab Retail South Westphalia 2020" we conducted a survey among LOOROs (May and July 2016) of the 26 partner cities of the region of South Westphalia in Germany. The questionnaire contained 42 questions with a 5-pointLikert-Scale and was answered by 124 participants via an online form and by 119 participants on paper. In total 243 questionnaires were submitted with 223 full data sets. For the analysis of the collected data and the evaluation of the research model we used SmartPLS [38]. Bootstrapping was done with 5000 samples and 223 cases, determining the significance of weights, loadings and path coefficients. SPSS was used for the multicollinearity tests of the formative constructs.

\subsection{Measurement Model}

The research model has one reflective construct ("Attitude towards Digitalization"). The other six constructs are formative so that different analyses are needed [39]. The significance of the constructs' indicators is assessed by their loadings (reflective constructs) that should be greater than 0.7 (greater than 0.6 is acceptable) or weights (formative constructs) that should be greater than 0.1 [37] and their t-values. An indicator is significant if its t-value is greater than 1.65. This corresponds to a significance level of $10 \%$. In order to reach a significance level of $5 \%(1 \%)$. the t-value must be greater than $1.96(2.57)$ [40]. Table 1 shows the tvalues as well as the corresponding loadings / weights for all indicators of our model and also indicates the result with regards to the calculated significance. Concerning the reflective construct, all indicators are significant. The AVE (Average Variance Extracted) is 0.5750 (minimum $>0.5$ ) and the composite reliability is 0.8428 (min. 0.7 ) so that the model fits to the convergence criteria. The discriminant validity of the constructs is also given. The model complies with the Fornell-Larcker criterion: Its highest squared construct correlation is with 0.3 below the maximum of 0.5 and the loadings of the reflective indicators are significantly higher than their cross loadings as compared to the other constructs. The internal consistency is given as the reflective construct exceeds the critical value of 0.7 for Cronbach's Alpha. Attitude towards Digitalization: 0.7515 [40]. The prediction validity Q2 is with 0.4323 higher than the minimum of 0 [41].

The results of the formative constructs are as follows: For the construct "Available Resources", two (R2, R4) of the six indicators have significant positive influences. The construct "Perceived External Pres- sure" includes three of four significant indicators: EP2, EP3 and EP4. The construct "Intention to Use Digital Sales Channels" comprises two of four significant indicators: IS2, IS3. For the construct "Intention to Use Digital Administration" three of four indicators have significant positive influences (IA2, IA3, IA4). The construct "Current Use of Digital Sales Channel" includes three of four significant indicators: US2, US3 and US4. And finally, for the construct "Current Use of Digital Administration" three of four indicators are significant: UA2, UA3, UA4 (table 1). In addition to the significance of indicators, the discriminant validity of the formative constructs must be verified. The highest correlation between the latent variables is given for the constructs "Intention to Use Digital Sales Channels" and "Current Use of Digital Sales Channels" with a value of 0.8995 . This does not exceed the set maximum of 0.9 so that the criterion regarding the discriminant validity is met [41]. The analysis conducted using SPSS with regard to multicollinearity showed that all indicators of the models are sufficiently different and independent of each other [41].

Table 1: Path Coefficient

\begin{tabular}{|c|c|c|c|c|c|}
\hline Indicator & $\begin{array}{l}\text { Loading } \\
\text { / Weight }\end{array}$ & $\begin{array}{c}t- \\
\text { statistics }\end{array}$ & $\begin{array}{c}\text { Sig- } \\
\text { nifi- } \\
\text { canc } \\
\text { e }\end{array}$ & VIF & $\mathrm{R}^{2}$ \\
\hline R1 & 0.0104 & 0.089 & ns & \multirow{4}{*}{ - } & \multirow{4}{*}{ - } \\
\hline R2 & 0.8274 & 9.6099 & $* * *$ & & \\
\hline R3 & -0.0342 & 0.2392 & ns & & \\
\hline $\mathrm{R} 4$ & 0.4094 & 2.4363 & $* *$ & & \\
\hline EP1 & -0.0634 & 0.4512 & ns & \multirow{4}{*}{ - } & \multirow{4}{*}{ - } \\
\hline EP2 & 0.3257 & 2.2084 & $* *$ & & \\
\hline EP3 & -0.573 & 3.8501 & $* * *$ & & \\
\hline EP4 & 0.7678 & 6.7553 & $* * *$ & & \\
\hline $\mathrm{A} 1$ & 0.8284 & 31.6562 & $* * *$ & \multirow{4}{*}{1.64} & \multirow{4}{*}{0.398} \\
\hline $\mathrm{A} 2$ & 0.7428 & 17.973 & $* * *$ & & \\
\hline A3 & 0.6412 & 10.046 & $* * *$ & & \\
\hline A4 & 0.8114 & 9.3633 & $* * *$ & & \\
\hline IS1 & 0.0771 & 0.85 & ns & \multirow{4}{*}{ - } & \multirow{4}{*}{0.067} \\
\hline IS2 & 0.3918 & 2.4835 & ** & & \\
\hline IS3 & 0.6875 & 4.8411 & $* * *$ & & \\
\hline IS4 & 0.0153 & 0.1447 & ns & & \\
\hline IA1 & 0.5818 & 5.5666 & $* * *$ & \multirow{4}{*}{ - } & \multirow{4}{*}{0.111} \\
\hline IA2 & 0.3082 & 1.831 & $*$ & & \\
\hline IA3 & 0.0734 & 0.8627 & ns & & \\
\hline IA4 & 0.4783 & 3.1103 & $* * *$ & & \\
\hline US1 & 0.0606 & 0.6482 & ns & \multirow{4}{*}{ - } & \multirow{4}{*}{0.809} \\
\hline US2 & 0.3614 & 2.2645 & $* *$ & & \\
\hline US3 & 0.7284 & 5.3362 & $* * *$ & & \\
\hline US4 & -0.0193 & 0.2012 & ns & & \\
\hline UA1 & 0.5358 & 4.8738 & $* * *$ & \multirow{4}{*}{ - } & \multirow{4}{*}{0.770} \\
\hline UA2 & 0.331 & 1.9906 & $* *$ & & \\
\hline UA3 & 0.1082 & 1.266 & $\mathrm{~ns}$ & & \\
\hline UA4 & 0.4949 & 3.2791 & $* * *$ & & \\
\hline
\end{tabular}

ns $=$ not significant; ${ }^{*} \mathrm{p}<0.10 ;{ }^{* *} \mathrm{p}<0.05 ; * * * \mathrm{p}<0.01$. 


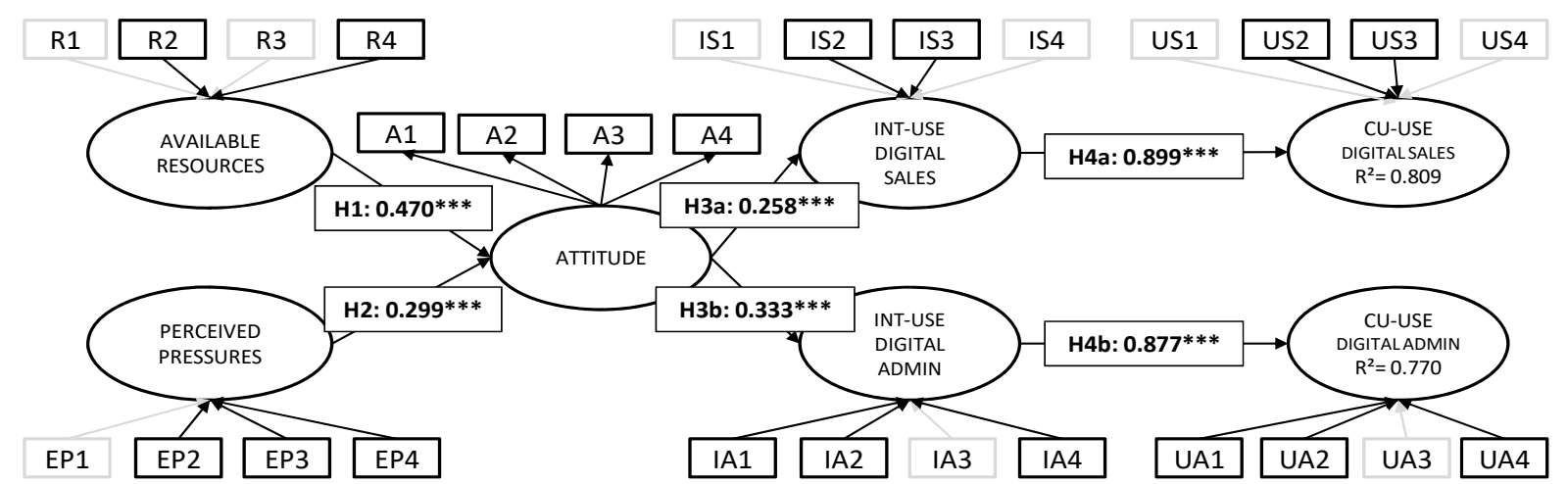

Figure 2: Research Model \& Analysis

\subsection{Structural Model}

In order to validate the model, the constructs with two or more influencing factors (only Attitude) were assessed using the variance inflation factor $(\mathrm{VIF}=1 /(1-$ $\left.\mathrm{R}^{2}\right)$ ) as to potential multicollinearity [42]. The VIF of "Attitude" (1.64) is lower than the required level of 5 and stays even below 3.333 which shows that there is no multicollinearity [43]. The value of $R^{2}$ represents the coefficient of determination which indicates a substantial influence if the value exceeds 0.67 . A value higher than 0.33 implies that a moderate influence of a latent independent variable on the dependent latent variable can be assumed. A weak influence is indicated by an $\mathrm{R}^{2}$ value of higher than 0.19 [44]. The coefficients of determination of the endogen constructs are all substantial: "Current Use of Digital Sales Channels" $\mathrm{R}^{2}=0.809$, "Current Use of Digital Administration" $\mathrm{R}^{2}=0.770$. The $\mathrm{t}$-values depicted in figure 3 and their path coefficients allow conclusions as to the validity of the formulated hypotheses. In sum, all stated hypotheses are highly significant $(* * *-p<0.01)$. The results of the hypotheses are as follows: H1, "Available Resources" has a positive influence on the "Attitude towards digitalization" ( $\mathrm{H} 1-$ effect size $\mathrm{f}^{2}=0.34$; effect size scale: $>0.02=$ low, $>0.15=$ medium, $>0.35=$ high). H2, "Perceived Pressure" has a positive influence on the "Attitude towards digitalization" (H2effect size $\mathrm{f}^{2}=0.13$ ). $\mathrm{H} 3 \mathrm{a}$, a positive "Attitude towards Digitalization" has a positive influence on the "Intention to Use Digital Sales Channels" (The effect size of $3 \mathrm{a}, \mathrm{b}$ and $4 \mathrm{a}, \mathrm{b}$ are not computable due to the model design). H3a, a positive "Attitude towards Digitalization" has a positive influence on the "Intention to Use Digital Administration". H4a, a high "Intention to Use Digital Sales Channels" has a positive influence on the "Current Use of Digital Sales Channels". H4b, a high "Intention to Use Digital Administration" has a positive influence on the "Current Use of Digital Admin- istration". Figure 2 shows all significant relations with a t-value of at least 1.65 [39].

\section{Discussion}

With the help of a survey conducted among 223 LOOROs in 26 cities in Germany, this study sheds light on the internal states of the owners of LOOROs and on the impacts of possible external triggers (Subsidies: offering resources, Regulations: creating pressure) on the current usage of digital tools and applications. To answer our first research questions: all stated hypotheses are confirmed and our findings show that LOOROs are receptive for the "Carrot-and-Stick Approach". LOOROs suffer from a shortage of resources and perceive pressure from their environment. With low resources and a high perception of pressure the prospects of success of a "Carrot-and-Stick Approach" are promising [9]. Both subsidies (adding resources) and regulations (creating pressure) will have impact on LOOROs digitalization efforts.

Going into further detail, in terms of resources, LOOROs face a shortage but they also face a situation of uncertainty. It appears that they do not know whether own resources are sufficient or not. All examined indicators (R1-R4) are characterized by high numbers of undecided answers (between $30 \%-43 \%$ ). Surprisingly only $24.4 \%$ (addition of disagree and strongly disagree of the descriptive results) do not see the ability to invest into digital tools and applications. This is in line with the results of the statistical analysis. Financial resources (R1) as well as knowledge resources (R3) are not significant indicators. However, the significant indicators (capacities (R2), time (R4)) show that resources which help to overcome LOOROs' operational limitations have an impact on the digitalization efforts. Furthermore, LOOROs perceive only low pressure to digitalize from their near environment. The indicator "competitive pressure" (EP1) is not signifi- 
cant and the perception of customer pressure towards digitalization (EP2 - 11.2\% - addition of agree and strongly agree of the descriptive results) is almost imperceptible. However, LOOROs do perceive pressure from the far environment e.g. legal regulations (EP3 $-54.3 \%)$ and a general pressure from the society (EP4 - 56\%). With regards to our results, LOOROs seem to be disconnected from their near environment, what leads to erroneous self-assessments and to the risk that the services provided by the LOOROs may not correspond to the competitive environment and the customer expectations $[1,8]$.

Nevertheless, the owners of LOOROs have a positive attitude towards digitalization, nearly $60 \%$ (addition of strongly agree and agree) think that "digitalization is good" (A1) and "easy to learn" (A2). 84\% think that digitalization will "play an important role in the future" (A3) and 52\% think that the digitalization will "increase their effectiveness" (A4) (all indicators are significant). However, our findings for the intention to use and the current use of digitalization show a contradicting picture: LOOROs still hesitate to adopt digital technologies and communicate only a low intention to do so in the future.

With regards to usage of digital tools and application on the sales channels, LOOROs report on low usage intentions for the significant indicators, just $12.6 \%$ (strongly agree and agree) have the intention to sell on third-party e-marketplaces (IS2). Referring to the lower boundary, only $8 \%$ have the intention to use in-store applications (IS3). For the not significant indicators, only $28 \%$ of the owners of LOROOs indicate the intention to use an own online shop (IS1), but surprisingly, nearly $41 \%$ state to use online advertisement in the future (IS4). The low intentions and the significance of the indicators are in line with our findings about the current usage: just $9 \%$ (very frequently and frequently) make use of third-party e-marketplaces (US2) to sell their products. The lowest point with $2.3 \%$ was reported for the use of in-store applications (US3) in the sales area. Finally only $13 \%$ of LOOROs use an own online shop (US1) and the highest current usage for the sales channels was reported with $22.4 \%$ for online advertisement (US4). It is uncertain whether LOOROs seem not to see the opportunities of the digital sales channels or if they consider themselves as not being able to implement digital tools and application and to run them successfully?

With respect to the use of digital tools and applications for the administration LOOROs demonstrate slightly stronger intentions. 59\% of owners of LOOROs (strongly agree and agree) intend to use administrative software (IA1). $62 \%$ have the intention to use inventory management systems (IA2). And 41\% seek to use digital payment systems (IA4). Referring to the current usage, our results show that $58.3 \%$ (very frequently and frequently) of owners of LOORO use software for the administration (UA1) and $56.1 \%$ use digital inventory management systems (UA2). The lowest usage is reported with $35 \%$ for the use of digital payment systems (UA4). The indicators "intention to use" and "current use" of digital communication system (IA3 \& UA3) are not significant.

In general the results show a higher tendency of LOOROs to use digital tools and applications for the administration to support their back-end activities than on the front-end sales channels with direct customer touch points. It appears that LOOROs are more open to digital solutions that support their day-to-day business, where they can feel the benefit (pace of work, convenience) right away than implementing digital tools and applications with customer touch points which seems to be more personally distanced and probably requires extra efforts in terms of customer care $[1,7]$.

\section{Implications}

Managerial Implications: Beside the examination of the carrot-and-stick approach our findings are providing insights for the owners of LOOROs: 1) Digital Strategy: The high numbers of uncertain answers in the conducted survey show that LOOROs need orientation and have a lack of strategy. The owners need to overcome this uncertainty with the development of digital strategies and an extended business model, ready for the digital age [6]. 2) Start with the back-end: Our results show a higher tendency for LOOROs to use digital tools and applications among the administrative back-end (e.g. software for the administration, inventory management systems). LOOROs should use their preference as a starting point; a strong digital infrastructure with integrated channels will empower all digital applications among the sales channels, too [7]. 3) Collaboration: To break the vicious circle of limitations in terms of capacities and time, LOOROs should search for collaborations among local partners and competitors. Shared digital services (e.g. customer app, delivery) and shared infrastructures (e.g. local shopping platforms) without the hassle of own organized implementation and maintenance are promising [6,7]. However, it is a vicious circle and may sound contradicting; the implementation of the suggested measures is time and effort consuming and will not pay off until an intense implementation- and training phase has been completed [45].

Political Implications: We conclude our study with the answer on our second research question: What are promising measures for a "Carrot-And-Stick" approach to foster the current use of digital tools and applications among LOOROs? Despite their undoubted 
importance, our findings show that it is not expedient to offer financial or educational incentives for a target group that suffers considerably under a shortage of time and capacities. Instead, the public sector should first develop local support structures that help LOOROs to overcome their operational limitations. Based on our findings, we suggest a carrot-and-stick approach on three levels: 1) Information \& Sensitization: LOOROs need to be reconnected to their near environment (customers, competition); information and sensitization campaigns as part of the regulatory body [12] about the digital developments in terms of tools and applications, industry standards [6] and customer needs and habits [1] are necessary to ensure that services provided by the LOOROs correspond to the competitive environment and the customer expectations $[1,8]$. 2) Collaboration \& Support: LOOROs need help to overcome their limitations (time, capacities) to be enabled to digitalize the business. Funding for collaboration platforms and infrastructures (e.g. local shopping platform) as well as for shared services (e.g. implementation, maintenance support for online shops and inventory management systems) could encourage collaboration among industry partners and competitors. [7,13]. 3) Legal Regulations: Finally LOOROs are receptive for legal regulations [12]. Regulations can steer LOOROs towards the use of digital tools and applications and reduce the administrative burden. Possible starting points could be legal requirements with regards to digital cashier systems (including inventory management and interfaces to online shops and third-party e-marketplaces) [45]. Furthermore, the introduction of standards (e.g. for product data provided by suppliers, to enable measures like shared product data databases, which provide standardized texts and pictures for LOOROs digital presence) is promising.

Research Implications: We have developed a new approach for an S-O-R Model which improves the organism $(\mathrm{O})$ section through the integration of the TRA / TPB core constructs instead of the conventionally used and often criticized bipolar PAD-Scale. This alternative S-O-R Model is particularly suitable for the analysis of technology adoption among organizations such as ME retailers and ME in general where decision making takes part on the individual-level.

\section{Limitations \& Future Outlook}

Due to their high involvement in daily operations of their business, owners of LOOROs are a difficult target group for a survey-based examination. Although we collected data from 223 LOOROs in 26 cities, the rather small sample size limits the explanatory power of our findings. Furthermore, the expressed uncertainty stated in the descriptive results show that LOOROs might not really know what resources are necessary or helpful to be well equipped for the challenges of digitalization. Hence, their view point towards resources and their expression of their actual needs could change once they face the digital challenges in the day-to-day operations of their business.

With regard to the findings of this research we suggest the following areas of future research: 1) Possible services for cooperation and collaboration among LOOROs. 2) Potentials of regulations based on standards for the retail sector to foster the digitalization of LOOROs. 3) Potentials of local e-marketplaces as cooperation platforms for LOOROs. And 4) possible elearning formats for further education for LOOROs.

\section{References}

[1] L.M. Bollweg, R. Lackes, M. Siepermann, and P. Weber, "Mind the Gap! Are local Retailers Misinterpreting Customer Expectations regarding Digital Services?", Journal on WWW/Internet 13 (1), IADIS, 2015, 17-29.

[2] HDE Retail Federation Germany, "Brief Profile", URL: http://einzelhandel.de/images/presse/Graphiken/HDE_Pr esentation eng.pdf/, (Accessed: 14/06/2016).

[3] IFH Köln, "Fast jedes zehnte Ladengeschäft von SchlieBung bedroht - alle Regionen betroffen", Stadt, Land, Handel 2020, URL: http://www.ifhkoeln.de/pressemitteilungen/details/fastjedes-zehnte-ladengeschaeft-von-schliessung-bedrohtalle-regionen-betroffen/,(Accessed: 14/06/2017).

[4] HDE Retail Federation Germany, URL: https://www.welt.de/wirtschaft/article165248634/Deutsc hlands-Innenstaedte-drohen-zu-veroeden.html, (Accessed: 14/06/2017)

[5] W. Liebmann, "Online Retailers Moving Into Offline Shopping -- Fast", URL: http://www.forbes.com /sites/wendyliebmann/2013/05/30/online-goes-offlinefast/, Forbes, New York City, 2013. (Accessed: 14/06/2017).

[6] IFH Köln, "Vitale Innenstädte 2016”, URL: https:/www.ifhshop.de/studien/handel-allgemein /208/vitale-innenstaedte-2016,(Accessed: 14/06/2017)

[7] V. Navickas, E. Krajňáková, and A. Navikaite, "Paradigm shift of small and medium-sized enterprises competitive advantage", Engineering Economics 26 (3), Kaunas University of Technology, Kaunas, 2015.

[8] L.M. Bollweg, R. Lackes, M. Siepermann, A. Sutaj, and P. Weber, "Digitalization of local owner operated retail outlets: The role of the perception of competition and customer expectations", Pacific Asia Conference on Information Systems, 2016.

[9] L.M. Salamon and O.V. Elliot, "The tools of government: A guide to the new governance", Oxford University Press, New York City, 2002.

[10] J. MIGUÉ, "Controls versus subsidies in the economic theory of regulation.", The Journal of Law and Economics, 20. Jg., Nr. 1, 213-221, 1977.

[11] J. Andreoni, W.T. Harbaugh, and L. Vesterlund, "The carrot or the stick: Rewards, Punishments and Coopera- 
tion", Department of Economics Working Paper No. 2002-1, University of Oregon, Eugene, 2002.

[12] S. Peltzman, M. Levine, and R. Noll, "The economic theory of regulation after a decade of deregulation.", Brookings papers on economic activity. Microeconomics, 1989, 1-59.

[13] C. Aktan and B. Dokuzcesmeler, "Regulatory Public Policies: An Introductory Survey.", The International Journal of Economics and Finance Studies (IJEFS) 8.2, 2016.

[14] L. Tornatzky, M. Fleischer and K. Alok, "Processes of technological innovation.” Lexington Books, Lexingtion 1990.

[15] K. Petrova and B. Wang, "Retailer adoption of mobile payment: A qualitative study." Journal of Electronic Commerce in Organizations (JECO), 11.4, 2013, 70-89.

[16] R. Rahayu and J. Day, "Determinant Factors of Ecommerce Adoption by SMEs in Developing Country. Evidence from Indonesia.” In Procedia - Social and Behavioral Sciences 195, 2015, 142-150.

[17] M. Kalkuhl, O. Edenhofer and K. Lessmann, "Renewable energy subsidies: Second-best policy or fatal aberration for mitigation?", Resource and Energy Economics, 35. Jg., Nr. 3, 2013,217-234.

[18] L. Latruffe, "Subsidies and technical efficiency in agriculture: Evidence from European dairy farms.", American Journal of Agricultural Economics, 2016, $77 \mathrm{ff}$.

[19] A, Enders, and T. Jelassi, "The converging business models of Internet and bricks-and-mortar retailers", European Management Journal 18(5), Elsevier, Amsterdam, 2000, 542-550.

[20] B. Ramdani, and P. Kawalek, "SME Adoption of Enterprise Systems in the Northwest of England - An Environmental, Technological, and Organizational Perspective", IFIP International Federation for Information Processing, Springer, Boston, 2007, 409-430.

[21] L. Liberman-Yaconi, T. Hooper, and K. Hutchings, "Toward a model of understanding strategic decisionmaking in micro-firms: exploring the Australian information technology sector", Journal of Small Business Management 48 (1), Wiley, Hoboken, 2010, 70-95.

[22] Mehrabian, A., and J.A. Russell, An approach to environmental psychology, the MIT Press, Cambridge, 1974.

[23] Y.J. Wang, M.S. Minor, and J. Wei, "Aesthetics and the online shopping environment: Understanding consumer responses", Journal of Retailing 87 (1), Elsevier, Amsterdam, 2011, 46-58.

[24] S. Lee, S. Ha, and R. Widdows, "Consumer responses to high-technology products: Product attributes, cognition, and emotions", Journal of Business Research 64 (11), Elsevier, Amsterdam, 2011, 1195-1200.

[25] S. Kim, G. Park, Y. Lee, and S. Choi, "Customer emotions and their triggers in luxury retail", Journal of Business Research 69 (12), Elsevier, Amsterdam, 2016, 5809-5818.

[26] R. Westbrook, "Product/consumption-based affective responses and postpurchase processes." Journal of marketing research, 1987, 258-270.

[27] J. Russell, J. Carroll, "On the bipolarity of positive and negative affect", Psychological, 1999, 125(1), 3-30.
[28] C. Stangor, "Affect, behavior, and cognition, Principles of Social Psychology", Flat World Knowledge, 2013.

[29] I. Bakker, T. van der Voordt, P. Vink, and J. de Boon, "Pleasure, arousal, dominance: Mehrabian and Russell revisited", Current Psychology 33 (3), Springer, Berlin, 2014, 405-421.

[30] Rogers, E.M., Diffusion of Innovation (4th ed.), Free Press, New York City, 2010.

[31] I. Ajzen, "The Theory of Planned Behavior", Organizational Behavior and Human Decision Processes 50 (2), Elsevier, Amsterdam, 1991, 179-211.

[32] F.D. Davis, R.P. Bagozzi, and P.R. Warshaw, "User acceptance of computer technology", Management Science 35 (8), INFORMS, Catonsville, 1989, 982-1003.

[33] I. Ajzen, and M. Fishbein, "Attitude-behavior relations", Psychological Bulletin 84 (5), American Psychological Association, Washington D.C., 1977, 888-918.

[34] M. Koufaris, "Applying the technology acceptance model and flow theory to online consumer behavior", Information systems research 13 (2), INFORMS, Catonsville, 2002, 205-223.

[35] B. Wernerfelt, "A resource-based view of the firm", Strategic Management Journal 5(2), Wiley, Hoboken, 1984, 171-180.

[36] Stapleton, T., et al., Complexity and the External Environment, The Open University, Milton Keynes (UK), 2000.

[37] C.B. Jarvis, S.B. Mackenzie, and P.M. Podsakoff, “A critical review of construct indicators and measurement model misspecification in marketing and consumer research", Journal of Consumer Research 30 (2), The Oxford University Press, Oxfort, 2013, 199-218.

[38] C. Ringle, S. Wende, and A. Will, SmartPLS 2.0.M3, SmartPLS, University of Hamburg, Hamburg, 2005.

[39] C. Fornell, and F.L. Bookstein, "Two structural equation models: LISREL and PLS applied to consumer exit-voice theory", Journal of Marketing Research 19 (4), JSTOR, New York City, 1982, 440-452.

[40] Hair, J.F., Multivariate data analysis (6th ed.), Prentice Hall, Englewood Cliffs, 2006.

[41] Hair, J.F., G. Hult, C. Ringle, and M. Sarstedt, A primer on partial least squares structural equation modeling (PLS-SEM), SAGE Publications, Thousand Oaks, 2014.

[42] Weiber, R., and D. Mühlhaus, Strukturgleichungsmodellierung: Eine anwendungsorientierte Einführung in die Kausalanalyse, Springer, Berlin, 2010.

[43] A. Diamantopoulos, and J.A. Siguaw, "Formative Versus Reflective Indicators in Organizational Measure Development", British Journal of Management 17 (4), Wiley, Hoboken, 1989, 263-282.

[44] H. Van der Heijden, T. Verhagen, and M. Creemers, "Understanding online purchase intentions", European Journal of Information Systems 12 (1), Springer, Berlin, 2003, 41-48.

[45] S. Kurnia, J. Choudrie, R.M. Mahbubur, and B. Alzougool, "A Malaysian grocery SME retail sector study", Journal of Business Research 68 (9), Elsevier, Amsterdam, 2015, 1906-1918. 